Advance Publication

\title{
INDUSTRIAL HEALTH
}

Received: May 14, 2021

Accepted: September 2, 2021

J-STAGE Advance Published Date: October 29, 2021 
Particle measurements of metal additive manufacturing to assess working occupational exposures: a comparative analysis of selective laser melting, laser metal deposition and hybrid laser metal deposition

\section{Enrico ODDONE ${ }^{1,2}$, Roberta PERNETTI ${ }^{1 *}$, Maria Lorena FIORENTINO ${ }^{3}$, Elena GRIGNANI $^{3}$, Daniele TAMBORINI ${ }^{4}$, Gianluca ALAIMO ${ }^{5}$, Ferdinando AURICCHIO ${ }^{6}$, Barbara PREVITALI ${ }^{4}$ and Marcello IMBRIANI ${ }^{1,2}$}

${ }^{1}$ Department of Public Health, Experimental and Forensic Medicine, University of Pavia, Italy

${ }^{2}$ Unità Operativa Ospedaliera di Medicina del Lavoro, ICS Maugeri, Italy

${ }^{3}$ Centro di Ricerche Ambientali, ICS Maugeri, Italy

${ }^{4}$ Department of Mechanical Engineering, Politecnico di Milano, Italy

${ }^{5}$ DIII, Department of Electrical, Computer and Biomedical Engineering, University of Pavia, Italy

${ }^{6}$ DICAR, Department of Civil Engineering and Architecture, University of Pavia, Italy

*Corresponding Author: Roberta Pernetti, Department of Public Health, Experimental and Forensic Medicine - University of Pavia, via Boezio 24, 27100 Pavia, Italy

roberta.pernetti@unipv.it, Tel. +390382593802 


\begin{abstract}
This paper presents the results of a measurement campaign for assessing the release of particles and the potential exposure of workers in metal additive manufacturing. The monitoring deals with three environments, i.e., two academic laboratories and one production site, while printing different metallic alloys for chemical composition and size. The monitored devices implement different metal 3D printing processes, named Selective Laser Melting, Laser Metal Deposition and Hybrid Laser Metal Deposition, providing a wide overview of the current laser-based Additive Manufacturing technologies. Despite showing the generation of metal powders during the printing processes, the usual measurements based on gravimetric analysis did not highlight concentrations higher than the international exposure limits for the selected metals (i.e., chromium, cobalt, iron, nickel, and copper). Additional data, collected through a cascade impactor and particle counter coupled with the achievements from previous measurements reported in literature, indicate that during the printing operations, fine and ultrafine metal particles might be generated. Finally, the authors introduced a preliminary characterisation of the particles released during the different phases of the investigated AM processes (powder charging, printing, part cleaning and support removal), highlighting how the different operations may affect the particle size and concentration.
\end{abstract}

\title{
Keywords
}

Additive manufacturing, Metal particle exposure, Occupational health, Metal particle release, Fine particles 


\section{Introduction}

The digitalisation of the industrial sector, one of the strategic objectives of the European Commission $^{1)}$ for the coming years, requires a significant transition of the production processes and one of the enabling key technologies for future developments is Additive Manufacturing (AM). As stated by ISO standard ASTM 52900:20192), AM technologies allow the production of complex objects through the addition of subsequent layers of material according to digital control based on 3D models. There are several studies that evaluate the occupational health risks of AM processes with thermoplastics, particularly due to the associated emissions of Volatile Organic Compounds (VOCs) ${ }^{3-8)}$. Another important branch of AM deals with the use of metals and metal alloys in production processes, mainly adopted by biomedical, aerospace, energy, tool, and mould sectors. In general, metal AM processes are based on an energy source used to melt or sinter the metal powders according to the design of the object. The standard ISO/ASTM 52900:2019²) classifies the AM processes based on the fusion of metallic feedstock in two categories: Powder Bed Fusion (PBF) and Directed Energy Deposition (DED). In the first category, the feedstock metal is a metallic round powder, evenly distributed onto a substrate plate using a coating mechanism and selectively melted by a high-energy source. In the DED processes, on the other hand, a metallic round powder is deposited and contemporaneously melted by the energy beam. When a laser beam is used as a high-energy beam, the two processes are called Selective Laser Melting (SLM) and Laser Metal Deposition (LMD) respectively. The initial powder diameter distribution is different for the two processes: SLM uses a finer powder distribution, in the range of $15-45 \mu \mathrm{m}$, while LMD uses a coarser powder in the range of $45-110 \mu \mathrm{m}$. However, as stated by Kolb et al..$^{9)}$, the initial size of the powders is reduced during SLM and LMD to subsize particles, ranging from the lung deposition $(\leq 10 \mu \mathrm{m})$ to the fine $(\leq 2.5 \mu \mathrm{m})$ powders and, in some specific cases, ultra-fine particles $(\leq 0.1 \mu \mathrm{m})$ and nano-particles (meaning particles with a diameter lower than $0.1 \mu \mathrm{m}$ produced by controlled engineering processes). 
The particle size distribution represents one of the main factors for evaluating the occupational risks during AM processes, since it influences the level of progression in the respiratory tract: finer particles can go deeper and reach lower regions (i.e., the lung), becoming more difficult to be disposed of by the organism and increasing the risk of inflammatory responses ${ }^{10)}$. In general, it has been estimated that a nasopharyngeal deposition occurs with an equivalent diameter of particles up to 100 $\mu \mathrm{m}$ (corresponding to the inhalable fraction as defined by the standard ISO $7708: 1995^{11}$ ), while lung deposition has been observed for intervals ranging from $0.001 \mu \mathrm{m}$ to $10 \mu \mathrm{m}^{12,13)}$ (corresponding to the respirable fraction according to the standard ISO $7708: 1995^{11)}$ ). Moreover, as analysed, the dimension of the particles determines the deposition time in the working environment ${ }^{14)}$ : fine particulate matter $(\mathrm{PM})$ remains scattered in the air volume for a shorter period in comparison to ultrafine particles (e.g. generated during SLM processes) ${ }^{15,16)}$ and can be detected for several hours after the end of the printing operations ${ }^{17)}$, also in relation to boundary conditions such as ventilation rate and relative humidity of the environment ${ }^{18)}$.

Although the release of fine and ultra-fine particles in AM processes have already been highlighted, since metal AM is an emerging technology, there are only a few studies that investigate the Indoor Air Quality (IAQ) and the associated occupational risks for the working environment of AM processes through in-field measurements ${ }^{19)}$. Sousa et al. ${ }^{20)}$ performed a review which focused on a set of specific keywords entailing occupational risks in metal additive manufacturing and exposures to nanoparticles, reporting only two works in line with the literature research. The conclusion of this review highlighted the need for further studies to introduce a systematic risk assessment for AM technology. Similar considerations are also reported in Leso et al. ${ }^{19)}$ as well as in Chen et al. ${ }^{8)}$, the latter also providing a comprehensive overview, through previous studies, of the evidence of PM release during the printing processes, risk assessment techniques and the impact on human health.

Other works investigated the effectiveness of different measurements and approaches for the assessment and characterisation of the PM in AM environments and the related risks, since fine and 
ultra-fine fractions may be difficult to detect using traditional techniques. In fact, these particles do not contribute significantly to the mass of the metal fractions settled on the filters used for gravimetric analysis, and in some cases, they may not even be caught. The application of mass-based filter analyses followed by inductively coupled plasma mass spectrometry (ICP-MS) for metal identification and coupled with particle counting instruments for measuring the number of fine, and ultrafine particles demonstrated a more comprehensive characterisation of the IAQ of the working environments $^{21)}$. Furthermore, the implementation of an integrated protocol for collecting, through questionnaires or dedicated interviews, practices and behaviour of the workers, machine utilisation and ventilation rate provides a comprehensive overview of the internal process organisation and environment to better evaluate the potential risk for workers ${ }^{22)}$. The proper characterisation of the fine and ultrafine particles released in AM is also important due to the current lack of standard limits and structured evaluations that would ensure the absence of potential occupational risks. In fact, the current reference limits provided by $\mathrm{ACGIH}^{23)}$, $\mathrm{OSHA}^{24)}$ and $\mathrm{NIOSH}^{25)}$, adopted at international level for monitoring the health levels of working environments, have been defined considering different production set-ups based on traditional technologies. A recent study demonstrated that, although measured values were in compliance with the dust levels provided by Swedish national law, in some cases (i.e., without targeted preventive measures, proper personal protective equipment and safety procedures) AM operators presented a concentration in the urine of chromium, cobalt, and nickel that was $20-30 \%$ higher than the administrative personnel of the company, showing an occupational exposure not fully controlled by the existing limits ${ }^{26}$. Therefore, there is a need for systematic studies on different metal AM set-ups in order to characterize particle release and to provide a structured knowledge about their features, and distribution over time and space, in order to support the definition process of reference benchmarks and standardised exposure limits ${ }^{27)}$.

This study contributes to these purposes, since it provides a systematic analysis and characterization of the particles released during two laser-based additive metal manufacturing processes, i.e., Selective 
Laser Melting (SLM) and Laser Metal Deposition (LMD), when different metallic powders are processed. The hybrid variant of LMD process (HYB) is also investigated, where the LMD printing process is combined with the milling subtractive operation. The evaluation was performed by coupling traditional techniques and gravimetric analysis with particle counters applied during different laser-based AM processes including charging of the powders, printing operation, cleaning, and drop-off of the complete printed objects. The data collection allowed the characterization of the size and distribution of the emitted particles during specific time intervals and the implementation of a set of preliminary considerations about the relationship between the operational phases, the printing process implemented, the configuration of the devices, the generated PM and their impact on the IAQ of the working environment.

\section{Materials and methods}

\section{Additive Manufacturing processes}

The AM printing devices were monitored within the activities of the European Regional Development Fund (ERDF) project MADE4LO ${ }^{28}$, aimed at developing the additive metal manufacturing sector in the Lombardy region, in Italy.

The Indoor Air Quality measurements were provided in three different facilities, two research laboratories at universities (Politecnico di Milano and University di Pavia) and one industrial premise (GFM at Nembro) where the following printers are used for research and production purposes: - two commercial SLM devices used for research, to develop the existing technologies and to optimise the processes, at the University of Pavia (PV_SLM) and at Politecnico di Milano (MI_SLM),

- an experimental LMD set-up developed for research purposes, at Politecnico di Milano (MI_LMD),

- two commercial devices used for industrial purposes, one based on LMD coupled with milling (NE_HYB) and one implementing SLM (NE_SLM) located in Nembro at GFM facilities. 
PV_SLM is a commercial model applying SLM, usually adopted within industrial processes. Within this work, the device is used for research purposes, to suggest technical improvements to the current SLM solutions. The printing process is held in an argon inert atmosphere, kept in slight overpressure conditions with respect to the external environment. The powders are supplied to the printing layer through a vertical fall enabled by gravity and are melted by a $200 \mathrm{~W}$ pulsed wave Yb:glass laser source. The cleaning operations are carried out manually through a dedicated door, which is also used for collecting the residual powders to be recycled. On the other hand, when the SLM chamber is open for operations such as set-up, piece removal and further cleaning, the operator wears personal protection equipment (PPE, i.e., overalls, shoe covers, single-use nitrile gloves and mask with appropriate filters).

MI_LMD is an experimental set-up implementing LMD printing process that is used for research purposes. It is composed of an anthropomorphic 8-axis system comprising a 6-axis robotic arm and a 2-axis roto-tilting table to produce free-form elements. At the end of the mechanic arm, there is the powder deposition head equipped with a $3000 \mathrm{~W}$ continuous wave $\mathrm{Yb}$ :glass laser source for melting the metal according to the design inputs. The printing device is surrounded by a $64 \mathrm{~m}^{3}$ closed box that guarantees laser protection according to the standard IEC EN 60825-4 ${ }^{29)}$. The charging of powder is performed manually by the operator inside the printing box by using a bin to charge the system's hopper from the powder containers. The cleaning operation is performed manually at the end of each part's production, by removing of the powders from the printed object with brushes (the powders are stored in cans to be recycled in new printing processes), then the environment is cleaned with a vacuum and finally the surfaces are wiped with alcohol. During all the operations, i.e., charging the powder, cleaning and any other intervention during printing, the operator wears PPE. Moreover, the chamber air is completely changed every 3 minutes by the air-circulation system, while fumes, vapours, and metallic particulate are suctioned and filtered before the air is released into the atmosphere. 
Within this study, MI_SLM is a commercial system that is applied for research purposes, aimed at optimising current SLM process solutions as well as at investigating new powders and advanced process challenges, such as process sensing and monitoring. The system is equipped with a $500 \mathrm{~W}$ continuous wave $\mathrm{Yb}$ :glass laser source and the printing chamber is filled with argon or nitrogen. Cleaning, sieving and powder recycling procedures are highly automated, and the workers interact with the device only for minor operations. The MI_SLM system is equipped with a closed powder circuit. After printing is finished, the operator cleans the building chamber using brushes without opening the chamber itself and then move the building and feeding cylinders into the cleaning station. Here, the cleaning and detaching of the printed part as well as powder removal are performed in a controlled environment, where the operator mostly works through external gloves in the closed chamber and also with PPE. The cleaning station provides the powder removal, sifting and the filling of the feeding cylinder.

NE_SLM and NE_HYB are commercial devices that are applied for industrial purposes and, within this study, are in a factory environment. NE_SLM is a commercial system implementing a Selective Laser Melting process. NE_HYB is a Laser Metal Deposition hybrid system, implementing two different systems for both additive and subtractive processes. In fact, it implements on the one hand a LMD unit for the 3D printing and, on the other, a milling unit for integrating the finishing operation in the mechanical process. The additive unit is equipped with a 2,500 $\mathrm{W}$ continuous wave diode laser, which is coupled with a supplier for the shielding gas (i.e., argon), used for transporting the metal powders during the printing process.

Table 1 summarises the main features of the monitored AM devices, Table A.1 of the Additional Materials includes more details about the powder composition.

\section{Exposure measurements}

The measurement strategy was based on the combined application of different techniques that provide a comprehensive overview of the particle exposure in the monitored environments. In particular, the 
set-up foresaw: gravimetric analyses with both fixed positions and personal sampling, analysis for specific granulometric fractions (five-stage cascade impactor) and real-time particle counting. The measurements were organised according to the current Italian standard UNI $689^{30)}$ and collected data during three different working days to ensure the representativeness of the gathered information in the AM facilities. There is an exception for the PV_SLM device which was monitored for two days, but also in this case all the phases of the printing process were implemented during the measurements. The fixed measurement points (including data collection for gravimetric analyses and particle counting) were installed in proximity of the printers where the operators work continuously and, in the case of MI_LMD, the monitoring also includes the internal part of the box where the printer is located.

\section{Method for sampling and gravimetric determination of dust fraction}

The sampling for the gravimetric analyses was collected through aspiration pumps calibrated according to the standard ISO 17025 $5^{31)}$ and a Mixed Cellulose Ester (MCE) Membrane Filter, with a diameter of $25 \mathrm{~mm}$ and porosity of $0.8 \mu \mathrm{m}$.

In particular, for the inhalable fraction, a conical inhalable sampler (CSI), operating with a flow rate equal to $1.4( \pm 0.1) 1 / \mathrm{min}$, was used. The respirable fraction was pre-selected by using a respirable dust cyclone as a particle fractionator (GS3 - SKC Inc., US) operating at a flow of $2.75( \pm 0.1) 1 / \mathrm{min}$, enabling the cut-off of the particles according to the standards ISO 7708:1995 ${ }^{11)}$ and CEN EN 481:1994 ${ }^{32)}$.

The gravimetric analysis was carried out under constant temperature and humidity conditions by applying the standards UNICHIM 1998:05 ${ }^{33)}$ and NIOSH $0500^{34)}$, for the inhalable dust fraction dust and NIOSH $0600^{35)}$, for the respirable fraction. The metals were analysed according to the methodology provided by the standard NIOSH 7300. In addition, a more detailed analysis for the definition of the granulometric classes was performed through a five-stage cascade impactor (Sioutas) with a sample flow rate of 9 1/min. The analysis adopted a Polytetrafluoroethylene (PTFE) filter with 
a diameter of $25 \mathrm{~mm}$ and porosity of $0.5 \mu \mathrm{m}$ as sampling substrate. The particles are separated and characterized according to the following four ranges of aerodynamic diameters: $>2.5 \mu \mathrm{m}, 1.0 \mu \mathrm{m}-2.5$ $\mu \mathrm{m}, 0.5 \mu \mathrm{m}-1.0 \mu \mathrm{m}, 0.25 \mu \mathrm{m}-0.5 \mu \mathrm{m}$. The time interval of each collected sample was established according to the duration of the monitored phase (charging, printing, cleaning) and ranges from 92 minutes to 480 minutes (whole day printing process).

The fractions collected through the Sioutas were analysed with the gravimetric method described for inhalable and respirable fractions.

\section{Real-time particle counting}

Coupled with the gravimetric analysis, the monitoring campaign dealt with the real-time characterisation of the particles emitted during the printing processes. The monitoring was performed through the aerosol particle counter Lasair III (Particle Measuring System, CO, USA). For the selected time interval, it allows the counting of the particles between $0.3 \mu \mathrm{m}$ and $25 \mu \mathrm{m}$, identifying the particle diameter according to different size channels (i.e., $0.3 \mu \mathrm{m}, 0.5 \mu \mathrm{m}, 1 \mu \mathrm{m}, 5 \mu \mathrm{m}, 10 \mu \mathrm{m}$, $25 \mu \mathrm{m})$. The particle counter was applied in the facilities of Milan and Nembro and monitored the processes of MI_LMD and GFM_SLM. The analysis allows the identification of the size and number of particles emitted during the phases of the different monitored AM processes and it was applied with a time-interval of 5 minutes.

\section{Results}

The results were collected through different monitoring campaigns organised within the ERDF project MADE4LO ${ }^{27)}$ from June 2019 to October 2020, with a focus on sample days representing the usual operation of the printing facilities.

\subsection{Gravimetric determination of dust fraction}

The gravimetric analyses were focused on the main relevant metals as identified within the measurements according to the alloys used during the different printing processes, and in particular: 
chromium $(\mathrm{Cr})$, cobalt $(\mathrm{Co})$, nickel $(\mathrm{Ni})$, iron $(\mathrm{Fe})$ and, for the devices NE_SLM and NE_HYB, the copper $(\mathrm{Cu})$ was also measured. Although the alloy used for NE_HYB does not contain copper, its concentration was investigated due to both the configuration of the printing environments, that are adjacent and separated only by a glass wall, and the operators' workflow, that is shared between the two devices. The collected values were compared with the international reference limits for exposure usually applied to the analysed metals: TLV (Threshold Limit Values), OSHA, NIOSH.

Table 2 summarises the results of the environmental monitoring campaign for the analysed AM facilities. In the case of MI_LMD, Table 2 reports both the values monitored within the printer box and outside it, next to the working desks where the operators control the printer processes and where the personnel circulate. This approach was taken because of the considerable volume of the box (i.e., $67 \mathrm{~m}^{3}$ ) and the observed practice, since the operators enter and exit the box during the printing process wearing proper PPE. In any case, the measured concentrations are significantly lower than the reference limits for all the considered metals. In general, the ratios between the monitored values and the limits range from $0.002 \%$ measured for the nickel in PV_SLM to 3.7\%, registered for the cobalt in PV_SLM as well.

Considering the limited ratio between the measured concentrations and reference limits for the inhalable dust fraction, it is not relevant to report the values for the respirable fraction in the text, either for environmental or personal monitoring (the results are included in the section dedicated to the additional materials - Table A.2 and Table A.3).

Table 3 reports the results of personal measurements taken during the usual operations (i.e., setup, cleaning, removal of the products, controls during printing processes), representing the actual exposure of the workers. As a general consideration, even in this case the gravimetric analysis does not highlight any critical conditions, since the ratio between the maximum registered values and the exposure limits ranges from $0.002 \%$ for the concentration of nickel in PV_SLM to $23.5 \%$ of cobalt in PV_SLM. In general, the ratio maximum /exposure limits for the personal measurement are higher 
than the environmental ones due to the close interaction with the printers during the operations. Moreover, the analysis did not highlight significant differences between the printing facilities used in research (PV and MI devices) and industrial environments (GFM devices).

Although the results reported in Table 2 and Table 3 do not highlight critical exposures, it is significant to compare the values measured in the environments where the $3 \mathrm{D}$ printers are located with a background room in the same building. Accordingly, it is possible to estimate what are the potential contributions caused by the AM processes to the metal concentration.

Although the collected values are substantially below the TLVs for the analysed metal particles, in some cases it is possible to highlight a significant increase of the measured concentration in comparison to the background. The median growth of the inhalable fraction particles ranges from 1.08 for iron, whose concentration is close to 0 in most of the background measurements, to 1.83 for nickel, which is also detected in the background. The impact of the printing operations is more significant for the respirable particles, since the median ratio between the concentrations in the printer room and the background ranges from 2.89 for iron to 5.54 for nickel.

Focusing on the metal powders released by each printer, Fig. 1 highlights a significant increase of iron and cobalt particles for inhalable fraction in PV_SLM (during the cleaning phase), while in MI_LMD the relevant increase deals with nickel and chromium (during the printing phase).

In fact, PV_SLM presents a cobalt particle concentration of $0.743 \mu \mathrm{g} / \mathrm{m}^{3}$ in the environment occurring during the cleaning operations and the powder sifting, and the corresponding personnel measurements highlight an exposure of $4.704 \mu \mathrm{g} / \mathrm{m}^{3}$. The highest cobalt concentration in MI_LMD was collected during the printing phase within the printing box $\left(0.286 \mu \mathrm{g} / \mathrm{m}^{3}\right)$, presenting a volume of $67 \mathrm{~m}^{3}$, while in the surrounding environments the values are lower $\left(0.059 \mu \mathrm{g} / \mathrm{m}^{3}\right)$. Nevertheless, the personnel sampling confirmed the higher exposure to cobalt of the operators $\left(0.859 \mu \mathrm{g} / \mathrm{m}^{3}\right)$ than in the other AM facilities, because of the need to enter the box during the printing or at the end of the process for routine actions. This confirms the importance of wearing PPE for the operators. 
Concerning the respirable fraction, the cobalt concentration rises in PV_SLM and MI_LMD respectively during the cleaning and printing phases. For the other metals, it is possible to highlight an increase of iron particles for NE_HYB during the printing phase, nickel for MI_SLM during printing and cleaning and chromium for MI_LMD during printing.

The gravimetric analysis was complemented with the characterisation of the particle size through the cascade impactor Fig. 2 shows the measured concentration for the analysed metals in the GFM facilities, for both the selective laser melting (GFM_SLM) and the hybrid (GFM_HYB) printers during the warm-up, the printing process, and the cleaning operation. The distributions between classes highlights for some metals (i.e., nickel, chromium, and cobalt) that particles with a diameter shorter than $0.5 \mu \mathrm{m}$ represent the highest fraction for both SLM and HYB printers during all the phases of the printing processes. The monitored iron particles present longer diameters since the main concentrations are respectively measured for powders with a diameter longer than 2.5 and $1-2.5 \mu \mathrm{m}$ for both the printers. Although the feedstock does not contain copper, small concentrations of this metal were also found during the printing operation of NE_HYB, mainly due to the adjacency with NE_SLM (whose printing alloy includes copper) and the interaction of the operators with both devices.

\section{Real-time particle counting}

The measurements with the particle counters were performed for the 3D printers in Polimi (i.e., MI_SLM and MI_LMD) and in Nembro (GFM_SLM and GFM_HYB) during the usual printing operations for sample days. This analysis aims to assess the number of particles of different sizes during a working day, identifying the variations associated with each phase of the printing processes. Fig. 3 and Fig. 4 show the results focusing on powders with a diameter of $0.3 \mu \mathrm{m}, 0.5 \mu \mathrm{m}$ and $1 \mu \mathrm{m}$.

Fig. 3 shows the results of the monitoring of one printing process within GFM facilities during the operation of the printer GFM_SLM. Before the monitoring, the operator carried out a complete cleaning process of the printing chamber. A significant number of particles with a diameter of $0.3 \mu \mathrm{m}$ 
and $0.5 \mu \mathrm{m}$ was observed, presenting different trends according to the monitored phase. In particular, the number of 0.3 particles increases during the printing operations and decreases slightly during pauses and the cleaning operation. On the other hand, the number of larger particles $(0.5 \mu \mathrm{m}$ and 1 $\mu \mathrm{m}$ ) increases during the cleaning operations and pauses, undergoing a decrease, more significant for $1 \mu \mathrm{m}$ particles, during the printing operation. Consequently, it is possible to highlight that the finest monitored particles $(0.3 \mu \mathrm{m})$ are released during the printing processes while, on the other hand, cleaning and pauses for set-up are associated with the release of larger particles $(0.5 \mu \mathrm{m}-1 \mu \mathrm{m})$, which may be raised by the actions of the operators.

Fig. 4 shows one printing day in Politecnico di Milano while the printer MI_LMD is operating. In particular, the monitoring includes the finalisation of one printing process, with the last 30 minutes of printing plus the removal of the final product and the complete development of a new one, from the positioning of a new sample towards the charging of powders and the final cleaning. This monitoring confirms the outcomes of the GFM_SLM, where it is possible to observe a general increasing trend of finest particles during the printing process, while the cleaning is associated with a decrease of $0.3 \mu \mathrm{m}$ particles and an increase of $0.5-1 \mu \mathrm{m}$ powders. In addition, during the monitoring of MI_LMD, the operators removed the final product of the first printing, positioned a new sample and charged the powders. The concentration of $0.3 \mu \mathrm{m}$ powders at the end of these phases is comparable to the initial one. On the other hand, the concentration of $0.5 \mu \mathrm{m}$ particles presents a slight increase that is constantly compensated during the printing phase until it reaches a constant value of around 150,000 particles $/ \mathrm{m}^{3}$.

\section{Discussion}

This study, coupling a gravimetric analysis with the particle size characterization, allows the provision of an added value to the information usually gathered through standard monitoring with gravimetric analysis. In this case, the characterization dealt with a more detailed definition of particle 
diameter for the monitored metals and the identification of the phase of release and allowed useful information to be provided for evaluating the potential risks for workers' health.

Results of gravimetric analyses highlighted a very low level of exposure, if any, in all monitored environments. The measured levels of PM were largely under the occupational exposure limits proposed by ACGIH, OSHA and NIOSH. Higher levels of cobalt were measured for PV_SLM (Table 3) and for MI_LMD, where the operators need to enter and exit the box during the printing process, but were, in any case, far from the threshold. These observations are consistent with other monitoring campaigns in AM facilities ${ }^{26)}$ where, although concentrations are largely under the most important OELs, mitigation measures are nonetheless suggested to minimise the occupational exposure to cobalt, due to its potential carcinogenicity in the presence of other metals ${ }^{36)}$. In addition, our results show that common methods of exposure assessment could be not fully comprehensive in AM work environments. High energies and temperatures involved in these processes could, in fact, lead to the production of metal dusts of very low diameter as byproducts ${ }^{16)}$. This feature could play an important role in exposure assessment, also considering that molecule surface is a function of particle size that increases exponentially when particle size decreases. Therefore, with equal concentrations, lower diameter particles provide a larger surface available for interactions with biological molecules and structures ${ }^{12)}$, possibly influencing the toxicology behaviour of metal dusts.

Furthermore, the size of the metal particulate, along with microclimatic boundary conditions ${ }^{17,18)}$, also affects its deposition times ${ }^{14)}$ : coarser particles such as those used in DED techniques remain suspended in the air for shorter times than finer ones used in production with SLM machines. The gathered data highlighted that the particle concentration presents a slow decrease, leading to suppose a deposition times of several hours, which might entail the progressive increase of the concentration over subsequent printing processes.

Thus far, several studies have warned about the negative impact of fine and ultrafine particles on human health ${ }^{13)}$, suggesting a precautionary approach and further investigations ${ }^{19)}$. These particles could affect workers' health not only by the uptake through inhalation, but also through dermal and 
ocular exposure. Inhalation and dermal exposure could entail both a local effect and a systemic effect through the distribution of metal particles to different organs by blood circulation and lymphatic systems, while ocular exposure could lead to eye and brain damage ${ }^{13)}$.

Moreover, it is worth noting that, in the monitored AM environments, particles of a smaller size $(0.3 \mu \mathrm{m})$ increase their concentration during the printing process (Fig. 3 and 4$)$ and reduce when the process stops, as opposed to $0.5-1 \mu \mathrm{m}$ particles. As reported in previous studies ${ }^{8,37)}$, the generated particles may undergo an agglomeration process, and the observed increase of the larger fractions during the monitoring may depend on it.

It is possible that the interruption of the printing phase for cleaning and charging the devices generates suitable boundary conditions that foster the particle agglomeration. More detailed measurements of the boundary conditions and their effects on the particle size are needed to verify this hypothesis.

This study did not measure nanosized particles. Nevertheless, the results of the gravimetric analysis and the concentration of particles ranging from $2.5 \mu \mathrm{m}$ to $0.3 \mu \mathrm{m}$ are in line with previous studies, where the presence of nanoparticles has also been detected. In fact, Ljunggren et al. ${ }^{26)}$, who observed concentrations of $0.3 \mu \mathrm{m}$ sized particles in the range $10-30 \times 10^{7}$ particles $/ \mathrm{m}^{3}$, which were consistent with our results, also measured noteworthy levels of nanoparticles.

Both fine and ultrafine particles can induce oxidative stress, mainly through the creation of oxygen-free radicals that can in turn affect lipid peroxidation, damage biological macromolecules and lead to the depletion of antioxidants. Furthermore, these molecular events can promote the activation of different cellular pathways, the expression of transcription factors for pro-inflammatory molecules and finally induce an inflammatory response that can lead to DNA damage, apoptosis and cell necrosis, with consequent pathological events of great importance ${ }^{8)}$. Some of the released metals (i.e., nickel, chromium) are considered carcinogenic agents ${ }^{38)}$, and thus identifying approaches for their reduction, even if below the OELs, is crucial for ensuring a safer working environment ${ }^{39)}$. 
As highlighted by a recent review paper ${ }^{19)}$, occupational exposures in AM deserve further investigation and, in particular, the evaluation of which AM process and printing phase produce a higher concentration of particles with shorter diameters. Our data, in fact, point out a concentration per cubic meter of $0.3 \mu \mathrm{m}$ particles in the SLM process about two-times greater than that of the LMD process, and thus, it could be of interest to compare fine and ultrafine particle emissions in different AM technologies as well (Fig. 3 and Fig. 4).

To prevent potential risks, wearing PPE and effective working routines are thus pivotal for avoiding detrimental exposures in workers. No biological monitoring on workers was planned within this study, in compliance with the regular health surveillance workers undergo if exposed to metal dusts as per Italian law 81/2008. Nevertheless, the operators involved in this study always used appropriate PPE, and thus, no real exposures to metal dust are likely to have occurred (Ljunggren $e t$ al., 2019) $)^{26)}$.

\section{Conclusions}

The results presented in this paper represent a first step towards the characterisation of the indoor air quality in AM facilities and the associated occupational risks. In general, the in-field observations in the three AM sites showed organised environments where the workers carefully operate the printers with a high level of protection by wearing appropriate PPE and implementing structured procedures. Moreover, the standard measurements for the evaluation of occupational risk, based on gravimetric analyses, did not highlight critical exposures.

Nevertheless, more accurate measurements with a cascade impactor and particle counter highlighted the presence of fine powders that are generated by the AM processes and that may have a significant impact on the general occupational risk of the AM working environment. The monitoring campaign allowed that the detection of different phases of the printing process release powders with different sizes, whose amount also depends on the type of printing device (i.e., SLM, LMD, HYB). Therefore, there is the need to organize structured measurement campaigns on different AM sites to 
improve the characterisation of metal particles released in the different printing phases and processes, also including nano particulate monitoring. Moreover, it is important to identify the boundary conditions and actions that have a significant impact on their concentration. Accordingly, it is relevant to define adequate preventive measures, on the one hand intervening on the technology by mechanising the most critical operations for the workers and, on the other hand, identifying the most effective mitigation actions (e.g., proper PPE, ventilation techniques, air change rate, etc.). Another future research question deals with the characterisation of the powder deposition time, according to the particle size and to the microclimate conditions of the environment. In fact, as a preliminary indication, the collected data show a slow reduction of the finest particle concentration, leading the assumption of deposition times lasting for several hours. Therefore, further investigations are needed to identify the deposition time accurately in order to determine when the operators need to wear PPE to avoid detrimental exposure.

Acknowledgements: This work was supported by the European Union, Repubblica Italiana, Regione Lombardia and FESR for the project MADE4LO (240963) under the call "POR FESR 2014-2020 ASSE I - AZIONE I.1.B.1.3”. The authors would thank Dr. Elena Fenili and Dr. Francesco Stortiero for their kind collaboration on data gathering. 


\section{References}

1) European Commission (2016) COM/2016/0180 Digitising European Industry Reaping the full benefits of a Digital Single Market.

2) ISO. ASTM52921-13 (2019) Standard Terminology for Additive Manufacturing - Coordinate Systems and Test Methodologies.

3) Afshar-Mohajer N, Wu C-Y, Ladun T, Rajon DA, Huang Y (2015) Characterization of particulate matters and total VOC emissions from a binder jetting 3D printer. Build Environ 93, 293-301.

4) Byrley P, George BJ, Boyes WK, Rogers K (2019) Particle emissions from fused deposition modeling 3D printers: evaluation and meta-analysis. Sci Total Environ 655, 395-407.

5) Davis AY, Zhang Q, Wong J, Weber R, Black M (2019) Characterization of volatile organic compound emissions from consumer level material extrusion 3D printers. Build Environ 160, 106209.

6) Gu J, Wensing M, Uhde E, Salthammer T (2019) Characterization of particulate and gaseous pollutants emitted during operation of a desktop 3D printer. Environ Int 123, 476-85.

7) Potter PM, Al-Abed SR, Lay D, Lomnicki SM (2019) VOC emissions and formation mechanisms from carbon nanotube composites during 3D printing. Environ Sci Technol 53, 4364-70.

8) Chen R, Yin H, Cole IS, Shen S, Zhou X, Wang Y, Tang S (2020) Exposure, assessment and health hazards of particulate matter in metal additive manufacturing: a review. Chemosphere 259, 127452.

9) Kolb T, Beisser R, Schmidt P, Tremel J, Schmidt M (2017) Safety in additive manufacturing: fine dust measurements for a process chain in laser beam melting of metals. RTejournal - Forum für Rapid Technologie 14.

10) Duffin R, Tran L, Brown D, Stone V, Donaldson K (2007) Proinflammogenic effects of lowtoxicity and metal nanoparticles in vivo and in vitro: highlighting the role of particle surface area and surface reactivity. Inhal Toxicol 19, 849-56. 
11) ISO (1995) ISO 7708:1995 Air quality — Particle size fraction definitions for health-related sampling

12 Oberdörster G, Oberdörster E, Oberdörster J (2005) Nanotoxicology: An emerging discipline evolving from studies of ultrafine particles. Environ Health Perspect 113, 823-39.

13) Chen R, Hu B, Liu Y, Xu J, Yang G, Xu D, Chen C (2016) Beyond PM2.5: The role of ultrafine particles on adverse health effects of air pollution. Biochim Biophys Acta 1860, 2844-55.

14) Kuijpers E, Bekker C, Brouwer D, le Feber M, Fransman W (2017) Understanding workers' exposure: systematic review and data-analysis of emission potential for NOAA. J Occup Environ Hyg 14, 349-59.

15) Fonseca AS, Maragkidou A, Viana M, Querol X, Hämeri K, de Francisco I, Estepa C, Borrell C, Lennikov V, de la Fuente GF (2016) Process-generated nanoparticles from ceramic tile sintering: Emissions, exposure and environmental release. Sci Total Environ 565, 922-32.

16) Mellin P, Jönsson C, Åkermo M, Fernberg P, Nordenberg E, Brodin H, Strondl A (2016) Nanosized by-products from metal 3D printing, composite manufacturing and fabric production. J Clean Prod 139, 1224-33.

17) Shi X, Chen R, Huo L, Zhao L, Bai R, Long D, Pui DYH, Rang W, Chen C (2015) Evaluation of nanoparticles emitted from printers in a lean chamber, a copy center and office rooms: health risks of indoor air quality. J Nanosci Nanotechnol 15, 9554-64.

18) Wang Y, Chen L, Chen R, Tian G, Li D, Chen C, Ge X, Ge G (2017) Effect of relative humidity on the deposition and coagulation of aerosolized $\mathrm{SiO} 2$ nanoparticles. Atmos Res 194, 100-8.

19) Leso V, Ercolano ML, Mazzotta I, Romano M, Cannavacciuolo F, Iavicoli I (2021) Threedimensional (3D) printing: implications for risk assessment and management in occupational settings. Ann Work Expo Health, wxaa146.

20) Sousa M, Arezes P, Silva F (2019) Nanomaterials exposure as an occupational risk in metal additive manufacturing. J Phys Conf Ser 1323, 012013. 
21) Graff P, Ståhlbom B, Nordenberg E, Graichen A, Johansson P, Karlsson H (2017) Evaluating measuring techniques for occupational exposure during additive manufacturing of metals: a pilot study: measuring occupational exposure during additive manufacturing of metals. J Ind Ecol 21, S120-S9.

22) Khaki S, Rio M, Marin P (2020) Monitoring indoor air quality in additive manufacturing environment. Procedia CIRP, 6.

23) ACGIH (2021) American Conference of Governmental Industrial Hygienists: TLVs and BEIs.

24) OSHA (2020) Occupational Safety and Health Administration. Permissible Exposure Limits.

25) NIOSH (2007) Pocket guide to chemical hazards.

26) Ljunggren SA, Karlsson H, Ståhlbom B, Krapi B, Fornander L, Karlsson LE, Bergström B, Nordenberg E, Ervik TK, Graff P (2019) Biomonitoring of metal exposure during additive manufacturing (3d Printing). Saf Health Work 10, 518-26.

27) Van Broekhuize P, Henk Streekstra W, Schulte P, Reijnders L (2012) Exposure limits for nanoparticles: report of an international workshop on nano reference values. Ann Occup Hyg 56, $515-24$.

28) Politecnico di Milano (2020) ERFD project MADE4LO. https://www.fondazionepolitecnico.it/en/initiatives/industry-4-0/made4lo/. Accessed July 1, 2021.

29) IEC (2006) IEC 60825-4:2006 - Safety of laser products - Part 4: Laser guards.

30) UNI (2018) UNI EN 689:2018 - Esposizione nei luoghi di lavoro - Misurazione dell'esposizione per inalazione agli agenti chimici - Strategia per la verifica della conformità coi valori limite di esposizione occupazionale. (in Italian)

31) UNI (2018) UNI CEI EN ISO/IEC 17025:2018. Requisiti generali per la competenza dei laboratori di prova e taratura. (in Italian)

32) NEN (1994) NEN-EN 481:1994 Workplace atmospheres - Size fraction definitions for measurement of airborn particles. 
33) UNICHIM (2013) Method UNICHIM 1998:05 - Ambienti di lavoro - Determinazione della frazione inalabile delle particelle aerodisperse - Metodo gravimetrico. 1998. (in Italian)

34) NIOSH (2013) National Institute for Occupational Safety and Health. NIOSH 0500 - Particulates not otherwise regulated, total. 1994.

35) NIOSH (1998) National Institute for Occupational Safety and Health. NIOSH 0600 - Particulates not otherwise regulated, respirable.

36) Wild P, Bourgkard E, Paris C (2009) Lung cancer and exposure to metals: The epidemiological evidence. Methods Mol Biol 472, 139-67.

37) Seipenbusch M, Binder A, Kasper G (2008) Temporal evolution of nanoparticle aerosols in workplace exposure. Ann Occup Hyg 52, 707-16.

38) IARC (2012) Monographs on the evaluation of carcinogenic risks to humans. Arsenic, Metals, Fibres, and Dusts. Vol. 100C, Lyon, France.

39) Nielsen GD, Ovrebø S (2008) Background, approaches and recent trends for setting health-based occupational exposure limits: a minireview. Regul Toxicol Pharmacol 51, 253-69. 


\section{Tables}

Table 1. Main features of the three analysed $3 \mathrm{~d}$ printers and processes

\begin{tabular}{|c|c|c|c|c|c|}
\hline & PV_SLM & MI_SLM & MI_LMD & NE_SLM & NE_HYB \\
\hline Location & $\begin{array}{l}\text { University of } \\
\text { Pavia }\end{array}$ & $\begin{array}{l}\text { Politecnico di } \\
\text { Milano }\end{array}$ & $\begin{array}{l}\text { Politecnico di } \\
\text { Milano }\end{array}$ & GFM-Nembro & GFM-Nembro \\
\hline Purpose & Research & Research & Research & Industry & Industry \\
\hline Printing process & SLM & SLM & LMD & SLM & Hybrid_LMD \\
\hline $\begin{array}{l}\text { Dimension of the } \\
\text { printing box }\left[\mathrm{m}^{3}\right]\end{array}$ & 0.019 & 5.40 & 67.00 & 0.032 & 1.6 \\
\hline Metal/Alloy used & $\begin{array}{l}\text { Stainless steel } \\
\text { AISI } 316 \mathrm{~L}\end{array}$ & $\begin{array}{l}\text { Maraging steel } \\
18 \mathrm{Ni} 300\end{array}$ & $\begin{array}{l}\text { Stainless steel } \\
\text { AISI 316L, } \\
\text { Inconel alloy } \\
\text { IN625 }\end{array}$ & $\begin{array}{l}\text { Stainless steel } \\
\text { AISI316L, } \\
\text { Inconel alloy } \\
\text { IN718 }\end{array}$ & $\begin{array}{l}\text { Stainless steel } \\
\text { AISI 316L, } \\
\text { Maraging } \\
\text { Steel 18Ni300 }\end{array}$ \\
\hline $\begin{array}{l}\text { Average particle } \\
\text { size of the raw } \\
\text { powders }[\mu \mathrm{m}]\end{array}$ & $15-45 \mu \mathrm{m}$ & $15-45 \mu \mathrm{m}$ & $50-90 \mu \mathrm{m}$ & $15-45 \mu \mathrm{m}$ & $45-120 \mu \mathrm{m}$ \\
\hline
\end{tabular}


Table 2. Measured environmental concentration of powders-inhalable fraction and comparison with the exposure reference limits (fixed position measurements)

\begin{tabular}{|c|c|c|c|c|c|c|}
\hline Metal & Printer & $\begin{array}{c}\text { Printing } \\
\text { process }\end{array}$ & $\begin{array}{l}\text { Median } \\
{\left[\mu \mathrm{g} / \mathrm{m}^{3}\right]}\end{array}$ & $\begin{array}{c}\text { Ranges of } \\
\text { measured } \\
\text { values } \\
{\left[\mu \mathrm{g} / \mathrm{m}^{3}\right]}\end{array}$ & $\begin{array}{c}\text { Exposure } \\
\text { reference } \\
\text { limits } \\
{\left[\mu \mathrm{g} / \mathbf{m}^{3}\right]}\end{array}$ & $\begin{array}{l}\text { Ratio Max } \\
\text { value } \\
\text { /Reference } \\
\text { limits } \\
\text { [\%] }\end{array}$ \\
\hline \multirow{5}{*}{$\mathrm{Cr}$} & PV_SLM & SLM & 0.090 & $0.020-0.091$ & \multirow{5}{*}{$\begin{array}{l}\mathrm{ACGIH}=500 \\
\mathrm{OSHA}=1000 \\
\mathrm{NIOSH}=500\end{array}$} & $0.009-0.018$ \\
\hline & MI_SLM & SLM & 0.287 & $0.099-0.491$ & & $0.025-0.050$ \\
\hline & MI_LMD & LMD & $0.119\left(0.085^{1}\right)$ & $0.072-0.491$ & & $0.049-0.098$ \\
\hline & NE SLM & SLM & 0.098 & $\begin{array}{c}\left(0.0 / 2-0.099^{\prime}\right) \\
0.049-0.120\end{array}$ & & $\begin{array}{c}\left(0.010-0.020^{1}\right) \\
0.012-0.024\end{array}$ \\
\hline & NE HYB & HYB & 0.081 & $0.064-0.095$ & & $0.017-0.026$ \\
\hline \multirow{5}{*}{ Co } & PV_SLM & SLM & 0.676 & $0.050-0.743$ & \multirow{5}{*}{$\begin{array}{l}\text { ACGIH }=20 \\
\text { OSHA }=100 \\
\text { NIOSH }=50\end{array}$} & $0.743-3.715$ \\
\hline & MI_SLM & SLM & 0.079 & $0.061-0.155$ & & $0.155-0.775$ \\
\hline & MI_LMD & LMD & $0.168\left(0.049^{1}\right)$ & $0.040-0.286$ & & $0.286-1.430$ \\
\hline & NE SLM & $\mathrm{S}$ & 0 & $\begin{array}{c}\left(0.040-0.059^{\prime}\right) \\
0.038-0.043\end{array}$ & & $\begin{array}{c}(0.059-0.293 \\
0.043-0.215\end{array}$ \\
\hline & NE HYB & HYB & 0.063 & $0.047-0.068$ & & $0.068-0.34$ \\
\hline \multirow{5}{*}{$\mathbf{N i}$} & PV_SLM & SLM & 0.025 & $0.015-0.025$ & \multirow{5}{*}{$\begin{array}{c}\text { ACGIH }=1500 \\
\text { OSHA }=1000\end{array}$} & $0.002-0.003$ \\
\hline & MI SLM & SLM & 1.244 & $0.347-1.625$ & & $0.108-0.163$ \\
\hline & MI_LMD & LMD & $1.402\left(0.925^{*}\right)$ & $0.677-10.389$ & & $0.693-0.572$ \\
\hline & NE SLM & SLM & 0.198 & $\begin{array}{c}\left(0.6 / 1-1.1 / 4^{\prime}\right) \\
0.177-0.255\end{array}$ & & $\begin{array}{c}(0.0 / 8-0.11 / 7) \\
0.017-0.026\end{array}$ \\
\hline & NE HYB & HYB & 0.248 & $0.196-0.258$ & & $0.017-0.026$ \\
\hline \multirow{5}{*}{$\mathbf{F e}$} & PV_SLM & SLM & 0.888 & $0.596-0.976$ & \multirow{5}{*}{$\begin{array}{l}\text { No limits } \\
\text { available }\end{array}$} & - \\
\hline & MI_SLM & SLM & 0.016 & $0.012-0.031$ & & - \\
\hline & MI_LMD & LMD & $0.012\left(0.010^{1}\right)$ & $\begin{array}{c}0.006-0.023 \\
\left(0.008-0.012^{1}\right)\end{array}$ & & - \\
\hline & NE_SLM & SLM & 0.235 & $0.196-0.261$ & & - \\
\hline & NE HYB & HYB & 0.330 & $0.328-0.550$ & & - \\
\hline \multirow[b]{2}{*}{$\mathbf{C u}$} & NE SLM & SLM & 0.056 & $0.011-0.065$ & \multirow{2}{*}{$\begin{array}{c}\text { ACGIH }=1000 \\
\text { OSHA }=1000 \\
\text { NIOSH }=1000\end{array}$} & 0.007 \\
\hline & NE_HYB & HYB & 0.071 & $0.058-0.207$ & & 0.021 \\
\hline
\end{tabular}

*The values in brackets are registered outside the printer box, next to the working desks, while the other values are measured within the MI_LMD printing box. 
Table 3. Personal measurements-inhalable fraction and comparison with the exposure reference limits

\begin{tabular}{|c|c|c|c|c|c|c|}
\hline Metal & Printer & $\begin{array}{l}\text { Printing } \\
\text { process }\end{array}$ & $\begin{array}{l}\text { Median } \\
{\left[\mu \mathrm{g} / \mathrm{m}^{3}\right]}\end{array}$ & $\begin{array}{c}\text { Ranges of } \\
\text { measured } \\
\text { values } \\
{\left[\mu \mathrm{g} / \mathrm{m}^{3}\right]}\end{array}$ & $\begin{array}{l}\text { Exposure } \\
\text { reference } \\
\text { limits } \\
{\left[\mu \mathrm{g} / \mathbf{m}^{3}\right]}\end{array}$ & $\begin{array}{c}\text { Ratio Max } \\
\text { value/Reference } \\
\text { limits [\%] }\end{array}$ \\
\hline \multirow{4}{*}{$\mathrm{Cr}$} & PV_SLM & SLM & 0.054 & $0.024-0.085$ & \multirow{4}{*}{$\begin{array}{l}\mathrm{ACGIH}=500 \\
\mathrm{OSHA}=1000 \\
\mathrm{NIOSH}=500\end{array}$} & $0.009-0.017$ \\
\hline & MI SLM & SLM & 0.238 & $0.214-0.262$ & & $0.003-0.005$ \\
\hline & MI LMD & LMD & 0.121 & $0.096-0.655$ & & $0.066-0.131$ \\
\hline & NE SLM/NE HYB & SLM & 0.087 & $0.020-0.341$ & & $0.034-0.068$ \\
\hline \multirow{4}{*}{ Co } & PV_SLM & SLM & 2.382 & $0.060-4.704$ & \multirow{4}{*}{$\begin{array}{l}\text { ACGIH }=20 \\
\text { OSHA }=100 \\
\text { NIOSH }=50\end{array}$} & $4.704-23.520$ \\
\hline & MI SLM & SLM & 0.475 & $0.170-0.780$ & & $0.780-3.900$ \\
\hline & MI LMD & LMD & 0.084 & $0.061-0.859$ & & $0.859-4.295$ \\
\hline & NE SLM/NE HYB & SLM & 0.059 & $0.037-0.130$ & & $0.130-0.650$ \\
\hline \multirow{4}{*}{$\mathbf{N i}$} & PV_SLM & SLM & 0.025 & $0.060-4.704$ & \multirow{4}{*}{$\begin{array}{c}\text { ACGIH }=1500 \\
\text { OSHA }=1000\end{array}$} & $0.002-0.003$ \\
\hline & MI SLM & SLM & 6.422 & $4.973-7.870$ & & $0.525-0.787$ \\
\hline & MI LMD & LMD & 1.048 & $0.333-8.528$ & & $0.569-0.853$ \\
\hline & NE_SLM/NE_HYB & SLM & 0.263 & $0.191-0.925$ & & $0.062-0.093$ \\
\hline \multirow{4}{*}{$\mathbf{F e}$} & PV_SLM & SLM & 3.083 & $0.363-5.802$ & \multirow{4}{*}{$\begin{array}{l}\text { No limits } \\
\text { available }\end{array}$} & \\
\hline & MI SLM & SLM & 0.208 & $0.034-0.382$ & & \\
\hline & MI LMD & LMD & 0.018 & $0.012-0.102$ & & \\
\hline & NE_SLM/NE_HYB & SLM & 0.663 & $0.150-0.924$ & & \\
\hline $\mathbf{C u} \mathbf{u}^{* *}$ & NE_SLM/NE_HYB & SLM & 0.06 & $0.003-0.193$ & $\begin{array}{c}\text { ACGIH }=1000 \\
\text { OSHA }=1000 \\
\text { NIOSH }=1000\end{array}$ & 0.019 \\
\hline
\end{tabular}

** The operators worked between the two printers simultaneously, thus it is not possible to separate the personal exposures between NE_SLM and NE_HYB 


\section{Figures}
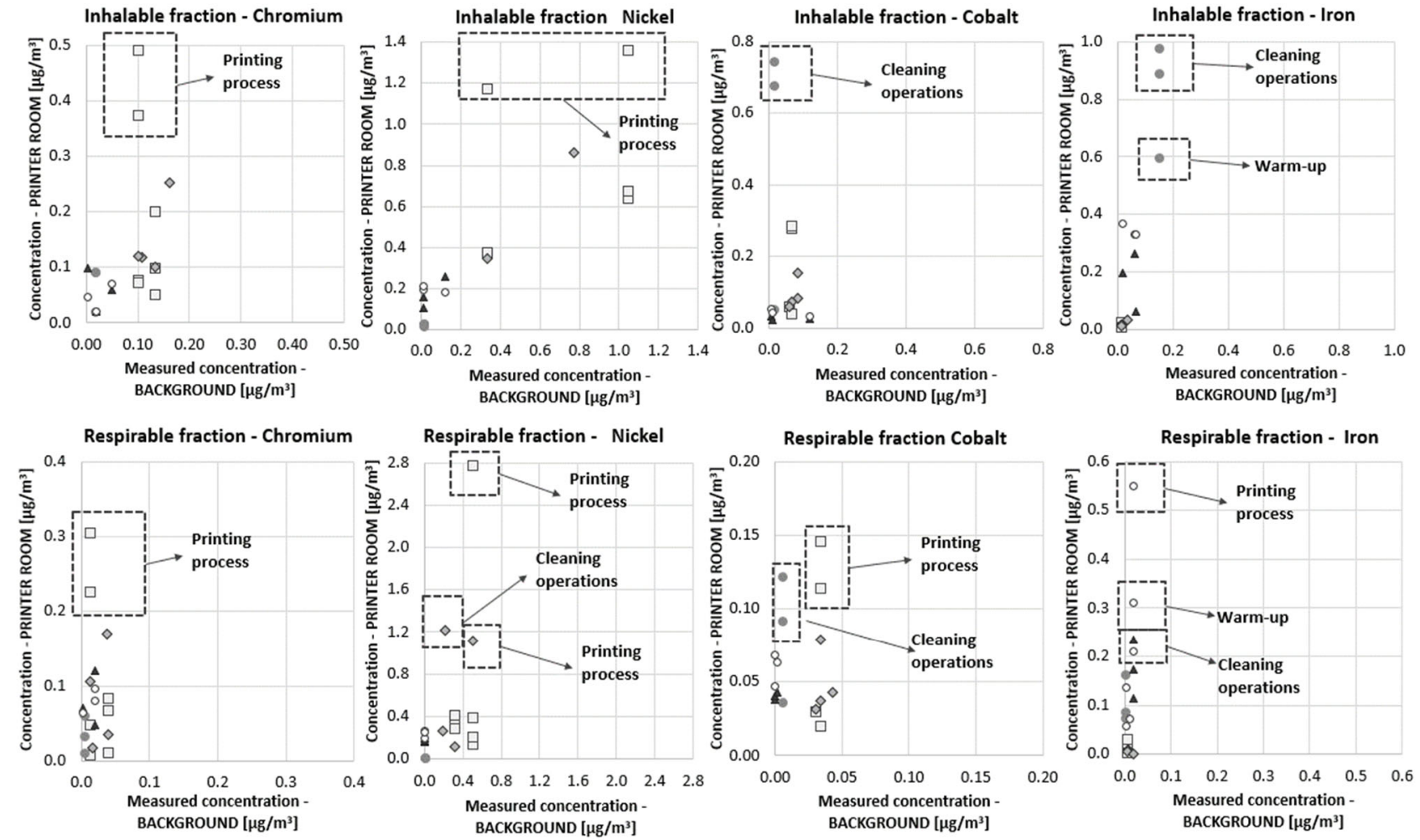

$\operatorname{TLV}(\mathrm{Cr})=500 \mu \mathrm{gg} / \mathrm{m}^{3} \quad \operatorname{TLV}(\mathrm{Ni})=1500 \mu \mathrm{g} / \mathrm{m}^{3} \quad \operatorname{TLV}(\mathrm{Co})=20 \mu \mathrm{g} / \mathrm{m}^{3} \quad \operatorname{TLV}(\mathrm{Cu})=200 \mu \mathrm{\mu g} / \mathrm{m}^{3}$

$\square \mathrm{MI} L \mathrm{LMD} \diamond \mathrm{MI}$ SLM $\bullet$ PV_SLM $\triangle$ NE_SLM $\circ \mathrm{NE}$ HYB

Fig. 1.
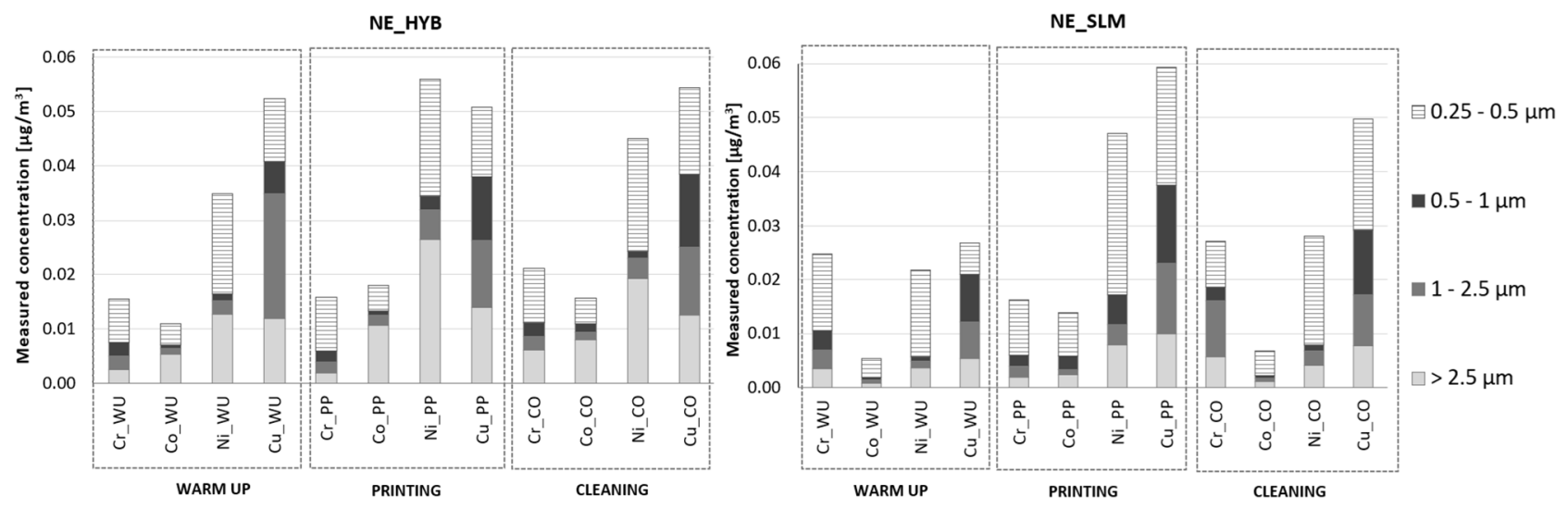

Fig. 2. 


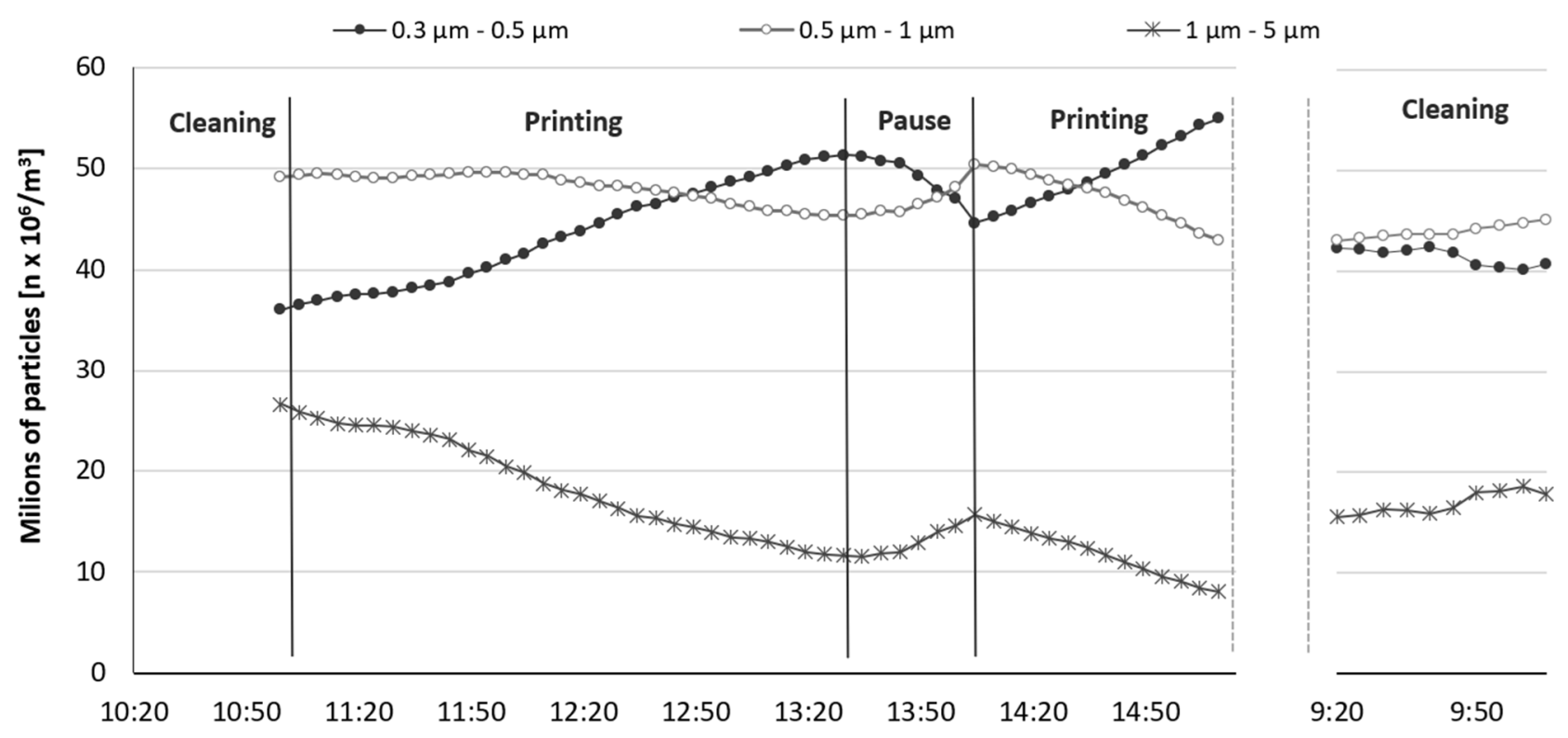

Fig. 3.

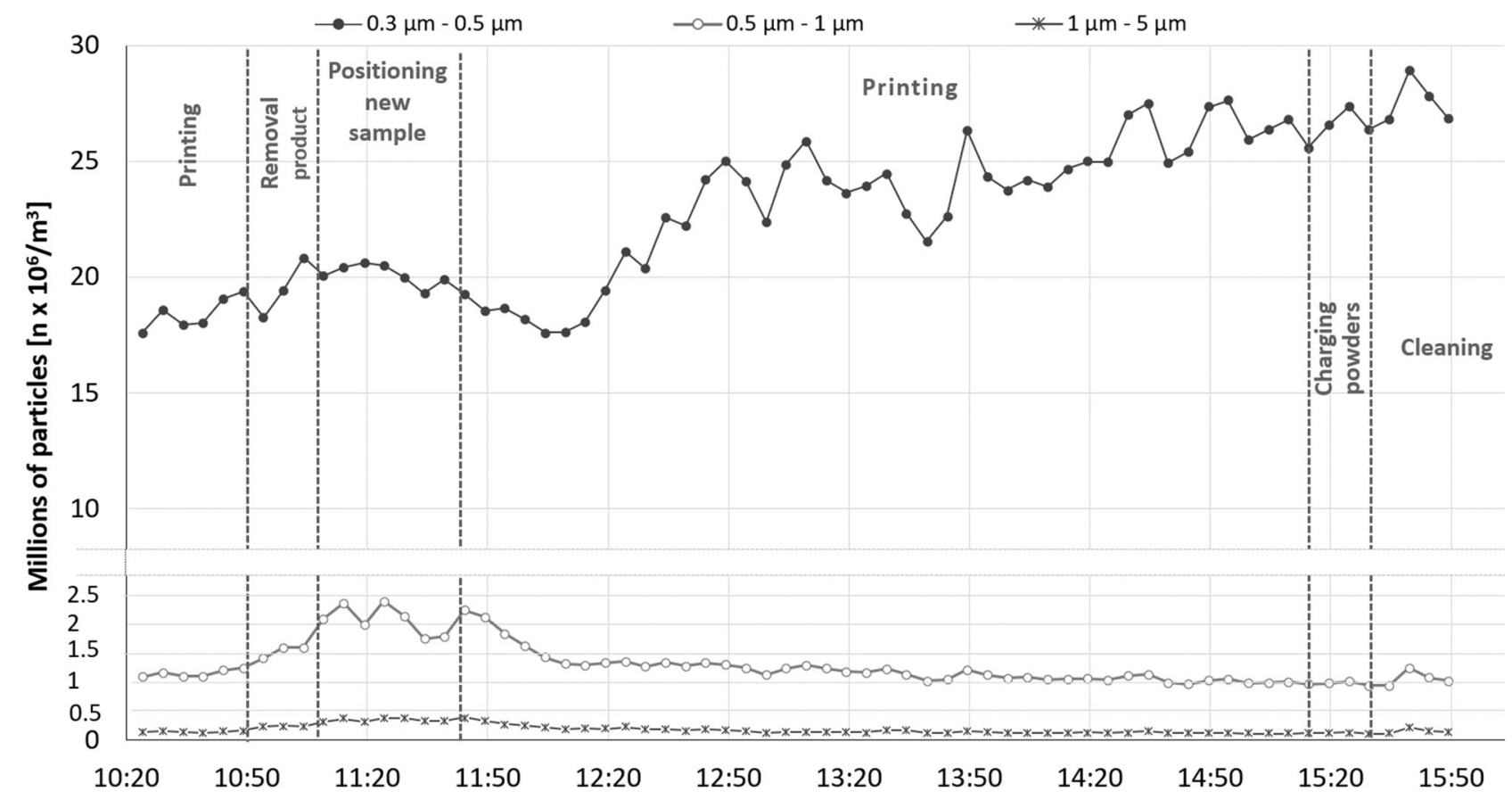

Fig. 4.

Fig. 1. Comparison between the concentration measured in a background environment and in the rooms where the 3D printers are located.

Fig. 2. Results of the particle size characterization with cascade impactor for the printers GFM_SLM and GFM_HYB.

Fig. 3. Real-time measurements of $0.3 \mu \mathrm{m}, 0.5 \mu \mathrm{m}$ and $1 \mu \mathrm{m}$ particles concentration in for GFM_SLM for two consecutive days. 
Fig. 4. Real-time measurements of $0.3 \mu \mathrm{m}, 0.5 \mu \mathrm{m}$ and $1 \mu \mathrm{m}$ particles concentration in MI_LMD for one printing day $(15.07 .2020)$ 